Article

\title{
Population Pharmacokinetics and Dose Optimization of Ceftazidime and Imipenem in Patients with Acute Exacerbations of Chronic Obstructive Pulmonary Disease
}

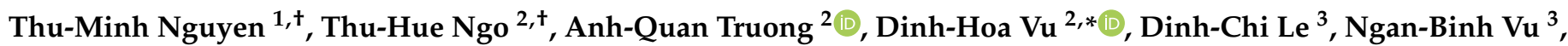
Tuyet-Nga Can ${ }^{1}$, Hoang-Anh Nguyen ${ }^{1,2}{ }^{-0}$, Thu-Phuong Phan ${ }^{4}$, Françoise Van Bambeke ${ }^{5}\left(\mathbb{D}\right.$, Céline Vidaillac ${ }^{6,7}$ and Quy-Chau Ngo ${ }^{4}$

check for updates

Citation: Nguyen, T.-M.; Ngo, T.-H.; Truong, A.-Q.; Vu, D.-H.; Le, D.-C.; Vu, N.-B.; Can, T.-N.; Nguyen, H.-A.; Phan, T.-P.; Bambeke, F.V.; et al. Population Pharmacokinetics and Dose Optimization of Ceftazidime and Imipenem in Patients with Acute Exacerbations of Chronic Obstructive Pulmonary Disease. Pharmaceutics 2021, 13, 456. https://doi.org/ 10.3390/pharmaceutics13040456

Academic Editor: Victor Mangas Sanjuán

Received: 28 February 2021

Accepted: 23 March 2021

Published: 27 March 2021

Publisher's Note: MDPI stays neutral with regard to jurisdictional claims in published maps and institutional affiliations.

Copyright: (c) 2021 by the authors. Licensee MDPI, Basel, Switzerland. This article is an open access article distributed under the terms and conditions of the Creative Commons Attribution (CC BY) license (https:/ / creativecommons.org/licenses/by/ $4.0 /)$.
1 Department of Pharmacy, Bach Mai Hospital, Hanoi 11519, Vietnam; nguyenminh802002@yahoo.com (T.-M.N.); ngaduoc@gmail.com (T.-N.C.); anhnh@hup.edu.vn (H.-A.N.)

2 National Drug Information and Adverse Drug Reaction Monitoring Centre, Hanoi University of Pharmacy, Hanoi 11021, Vietnam; 1401263@hup.edu.vn (T.-H.N.); 1401502@hup.edu.vn (A.-Q.T.)

3 Department of Analytical Chemistry, Hanoi University of Pharmacy, Hanoi 11021, Vietnam; child@hup.edu.vn (D.-C.L.); binhvn@hup.edu.vn (N.-B.V.)

4 Respiratory Center, Bach Mai Hospital, Hanoi 11519, Vietnam; thuphuongdr@gmail.com (T.-P.P.); ngoquychaubmh@gmail.com (Q.-C.N.)

5 Louvain Drug Research Institute, Université catholique de Louvain, B1.73.05, B-1200 Brussels, Belgium; francoise.vanbambeke@uclouvain.be

6 Center for Tropical Medicine and Global Health, University of Oxford, Oxford OX3 7LG, UK; cvidaillac@oucru.org

7 Oxford University Clinical Research Unit, University of Oxford, Ho Chi Minh City 72700, Vietnam

* Correspondence: vudinhhoa@gmail.com or hoavd@hup.edu.vn; Tel.: +84-904-250745

$+\quad$ These authors contributed equally to this work.

Abstract: Background: Ceftazidime and imipenem have been increasingly used to treat Acute Exacerbations of Chronic Obstructive Pulmonary Disease (AECOPD) due to their extended-spectrum covering Pseudomonas aeruginosa. This study aims to describe the population pharmacokinetic $(\mathrm{PK})$ and pharmacodynamic (PD) target attainment for ceftazidime and imipenem in patients with AECOPD. Methods: We conducted a prospective PK study at Bach Mai Hospital (Viet Nam). A total of 50 (ceftazidime) and 44 (imipenem) patients with AECOPD were enrolled. Population PK analysis was performed using Monolix 2019R1 and Monte Carlo simulations were conducted to determine the optimal dose regimen with respect to the attainment of $60 \%$ and $40 \% f \mathrm{~T}>\mathrm{MIC}$ for ceftazidime and imipenem, respectively. A dosing algorithm was developed to identify optimal treatment doses. Results: Ceftazidime and imipenem PK was best described by a one-compartment population model with a volume of distribution and clearance of $23.7 \mathrm{~L}$ and $8.74 \mathrm{~L} / \mathrm{h}$ for ceftazidime and $15.1 \mathrm{~L}$ and $7.88 \mathrm{~L} / \mathrm{h}$ for imipenem, respectively. Cockcroft-Gault creatinine clearance represented a significant covariate affecting the clearance of both drugs. Increased doses with prolonged infusion were found to cover pathogens with reduced susceptibility. Conclusions: This study describes a novel and versatile three-level dosing algorithm based on patients' renal function and characteristic of the infective pathogen to explore ceftazidime and imipenem optimal regimen for AECOPD.

Keywords: chronic obstructive pulmonary disease; acute exacerbations; ceftazidime; imipenem; dose optimization; Pseudomonas aeruginosa

\section{Introduction}

Chronic obstructive pulmonary disease (COPD) is a condition where progressive and irreversible structural changes of the airways lead to airflow obstruction and persistent respiratory symptoms including shortness of breath, cough, and expectorations [1]. COPD is mainly caused by exposure to harmful particles or fumes such as tobacco smoking and air pollution, two major and global burdens [1]. With an estimated 328 million people 
presenting moderate to severe COPD worldwide, the condition is considered as a major health and economic concern globally, and more specifically in low- and middle-income countries (LMICs) where almost $90 \%$ of worldwide COPD deaths are reported [2,3]. Approximately $7.1 \%$ of the Vietnamese population (nearly 6.8 million people) have COPD [4]. These patients occupy roughly $25 \%$ of the beds in the respiratory wards of hospitals, at our institution [5], and nationwide [4].

Due to the heterogeneity of its pathogenesis and its overlapping clinical manifestations, COPD is difficult to manage [6]. Patients are at risk of experiencing sudden episodes of breathing difficulty associated with a chesty cough, significantly affecting the progression of the disease and the patients' quality of life [7]. Patients with acute exacerbations of COPD (AECOPD) are at higher risk of treatment failure [8], future readmissions [9], and death [10]. Unfortunately, these events are difficult to predict and control due to their large variety of etiologies and clinical presentations [11,12]. Up to $30 \%$ of the AECOPD are idiopathic, while 50 to $70 \%$ are triggered by respiratory viral infections [13-16]. Concomitant shortterm antibiotic therapy is however indicated when patients with AECOPD present an increase in dyspnea and production of purulent sputum, a sign of a growing bacterial burden in the airways [1]. The choice of antibiotic is based on the local bacterial resistance epidemiology [1,12] with typically an initial empirical treatment with aminopenicillin combined with clavulanic acid, or a macrolide or tetracycline agent [1]. For patients with a history of frequent exacerbations, severe airflow obstruction, and/or requiring mechanical ventilation, microbiological analysis is recommended to identify the pathogen present and its drug susceptibility profile [1,12].

Pseudomonas aeruginosa is one of the most common species found in the sputum of patients with AECOPD $[17,18]$. It is unclear whether it is a cause or a consequence of AECOPD, however, it is recognized that its presence in the sputum of patients represents a risk factor for severe exacerbation, poorer clinical outcomes, prolonged hospitalization, and increased cost $[19,20]$. Despite the lack of clinical evidence to demonstrate the benefit of targeting $P$. aeruginosa to reduce the risk of exacerbations, anti-Pseudomonas agents are commonly used to treat severe AECOPD where the pathogen is suspected or confirmed [21]. At our institution where P. aeruginosa is commonly found in our patients population [22], anti-Pseudomonas drugs including ceftazidime (CAZ), imipenem (IMI), meropenem, piperacillin/tazobactam are used to manage over $50 \%$ of hospitalized COPD patients, whether microbiological results are available or not [23]. Epidemiology studies performed at our institution have revealed that local strains of $P$. aeruginosa are mainly susceptible to CAZ and IMI. This observation has guided our physicians to use these 2 antimicrobials routinely but has also raised the concern of their optimal usage in the AECOPD patients to preserve their efficacy and reduce the pressure of selection [22,23].

Clinical/pharmacokinetic prediction models are powerful tools to guide infectious disease physicians and pharmacists in the selection of optimal dosing regimens [24]. Limited clinical data are available on the pharmacokinetics (PK) and pharmacodynamics (PD) of CAZ and IMI in patients presenting AECOPD. It is therefore difficult to confirm that the doses currently used in this population are optimal. The aims of this study are to 1) collect CAZ and IMI PK data in AECOPD patients, 2) develop a PK model that best describes the time course of drug exposure in this specific population, and 3) describe how patients and pathogen characteristics influence optimal dosing regimens of these 2 antibiotics. The long-term goal of this study is to raise our physicians but also the global community's awareness of the existing gap(s) in terms of CAZ and IMI use and dose optimization to better manage AECOPD and reduce the risk of emergence of antimicrobial resistance.

\section{Materials and Methods}

\subsection{Study Design and Participants}

This study was prospectively performed at the Respiratory department (116 beds) of Bach Mai Hospital (2400 beds) between August 2018 and March 2019. To be eligible, patients must be (1) aged over 18, (2) presenting AECOPD matching the definition of 
the Global initiative for chronic obstructive lung disease 2020 (i.e., an acute worsening of respiratory symptoms that results in additional therapy) [1] and (3) receiving CAZ or IMI therapy for at least three consecutive days. Only patients who did not sign a consent were excluded. The study was conducted according to the guidelines of the Declaration of Helsinki and approved by the Institutional Review Board of Bach Mai hospital (reference \# 2919/QD-BM for the protocol BM-2017-957-50, approval date on 26 December 2017). Written informed consent was obtained from all patients or their legal representatives.

\subsection{Sample Collection and Analysis}

Prescription and dosing regimens (IMI: $0.5 \mathrm{~g}$ q12h, $0.5 \mathrm{~g} \mathrm{q} 8 \mathrm{~h}, 0.5 \mathrm{~g} \mathrm{q} 6 \mathrm{~h}, 1 \mathrm{q}$ q12h and $1 \mathrm{~g}$ q8h; CAZ: $1 \mathrm{~g}$ q12h, $1 \mathrm{~g} \mathrm{q} 8 \mathrm{~h}, 1 \mathrm{~g} \mathrm{q} 6 \mathrm{~h}, 2 \mathrm{~g} \mathrm{q} 12 \mathrm{~h}$ and $2 \mathrm{~g} \mathrm{q} 8 \mathrm{~h}$ ) were at the discretion of the physicians based on routine care practices. Clinical data including patient characteristics, antibiotic used, and microbiological results were collected at baseline and on the days of PK sampling. Due to cultural challenges, our pharmacokinetic study used a sparse sampling strategy with 2 samples per patient. Samples were collected at least $30 \mathrm{~min}$ after infusion of the third dose to ensure a steady-state was attained and one to two hours prior to the 4th dose. Blood samples $(3 \mathrm{~mL})$ were collected into a heparinized vacutainer and centrifuged immediately to obtain plasma. To improve stability of IMI, plasma sample $(1 \mathrm{~mL})$ was mixed (1:1, v/v) with $0.5 \mathrm{M}$ 3-morpholino-propane-sulphonic acid buffer (MOPS, pH 6.8, Sigma-Aldrich, Co., St. Louis, MO, USA) and stored at $-40{ }^{\circ} \mathrm{C}$ until sample analysis. Analysis was performed within 1 week at the Department of Analytical Chemistry and Toxicology of Hanoi University of Pharmacy to determine CAZ and IMI concentrations by validated high-performance liquid chromatography using Agilent 1200 equipped with a PDA detector (Agilent Technologies, Santa Clara, CA, USA) [25,26].

For quantification of CAZ concentration, $100 \mu \mathrm{L}$ aqueous solution of cefepime (National Institute of Drug Quality Control, Hanoi, Vietnam) $(200 \mu \mathrm{g} / \mathrm{mL})$ as internal standard was mixed to $200 \mu \mathrm{L}$ of plasma. Acetonitrile (Merck KGaA, Darmstadt, Germany) (500 $\mu \mathrm{L}$ ) was added to the mixture for protein precipitation. The sample was then vortexed for $30 \mathrm{~s}$ and centrifuged at $14,000 \mathrm{rpm}$ for $5 \mathrm{~min}$. The resulting supernatant $(800 \mu \mathrm{L})$ was transferred into an Eppendorf tube containing $500 \mu \mathrm{L}$ of chloroform. The tube was vortexed for $30 \mathrm{~s}$ and then centrifuged at $1700 \mathrm{rpm}$ for $5 \mathrm{~min}$. A sample $(20 \mu \mathrm{L})$ of the upper aqueous extract was injected into the Agilent 1200 chromatography system using an Inerstil ${ }^{\circledR}$ ODS -3 column (GL Sciences Inc., Tokyo, Japan) $(250 \mathrm{~mm} \times 4.6 \mathrm{~mm} ; 5 \mu \mathrm{m})$. The mobile phase consisted of a mixture $(9: 1, v: v)$ of sodium dihydrogenophosphate (Merck KGaA, Darmstadt, Germany) (50 mM, pH 3.2) and acetonitrile that was maintained at a flow rate of $1.5 \mathrm{~mL} / \mathrm{min}$. UV detection was set at $260 \mathrm{~nm}$ for recording chromatograms. The method was proven to be reproducible with bias of $1.8 \%, 7.2 \%,-6.1 \%$ and $1.4 \%$ and precision of $5.5 \% ; 2.1 \%, 2.5 \%$, and $2.2 \%$ at concentrations of $2,6,50$, and $80 \mu \mathrm{g} / \mathrm{mL}$, respectively. The lower limit of quantification was $2 \mu \mathrm{g} / \mathrm{mL}$ and the method was linear over the range of 2 to $100 \mu \mathrm{g} / \mathrm{mL}$ [25].

For quantification of IMI concentrations, $100 \mu \mathrm{L}$ of meropenem $(20 \mu \mathrm{g} / \mathrm{mL})$ as internal standard was mixed to $200 \mu \mathrm{L}$ of plasma and $200 \mu \mathrm{L}$ of $0.5 \mathrm{M}$ MOPS buffer $\mathrm{pH} 6.8$. Acetonitrile $(500 \mu \mathrm{L})$ was added to the mixture for protein precipitation. The sample was then vortexed for $30 \mathrm{~s}$ and centrifuged at $6500 \mathrm{rpm}$ for $10 \mathrm{~min}$. The resulting supernatant $(500 \mu \mathrm{L})$ was evaporated under a nitrogen stream and the residual was dissolved in $200 \mu \mathrm{L}$ $0.5 \mathrm{M}$ MOPS buffer $\mathrm{pH}$ 6.8. A sample $(50 \mu \mathrm{L})$ of the resulting solution was injected into a Supelco Ascentis ${ }^{\circledR}$ C8 guard column (Supelco, Bellefonte, PA, USA) $(20 \times 4 \mathrm{~mm} ; 5 \mu \mathrm{m})$ and a C8 Supelco Ascentis ${ }^{\circledR}$ C8 HPLC column $(150 \times 4.6 \mathrm{~mm} ; 5 \mu \mathrm{m})$ (Supelco, Bellefonte, PA, USA). The analytes were eluted at a flow rate of $1 \mathrm{~mL} / \mathrm{min}$ with ultraviolet detection at $298 \mathrm{~nm}$ using a mobile phase consisting of phosphate buffer (0.05 M, pH 7.4) and methanol. The proportion of phosphate buffer in solvent gradient was as followed: $0-4 \mathrm{~min}: 96 \%$; 4-7 min: decrease from $96 \%$ to $30 \%$; 7-9 min: stable at 30\%; after 9 min: increase from $30 \%$ to $96 \%$. The method was proven to be accurate and precise with bias of $0.9 \%,-11.8 \%$, $-2.5 \%$, and $5.45 \%$ and precision of $7.5 \%, 3.2 \%, 9.9 \%$, and $10.7 \%$ at concentrations of $0.5,1$, 
20 , and $40 \mu \mathrm{g} / \mathrm{mL}$, respectively. The lower limit of quantification was $0.5 \mu \mathrm{g} / \mathrm{mL}$ and the method was linear over the range of 0.5 to $50 \mu \mathrm{g} / \mathrm{mL}$ [26].

\subsection{Population Pharmacokinetic Modelling}

Population PK analysis was performed using MONOLIX software (Monolix version 2019R1. Antony, France: Lixoft SAS, 2019.). Population PK parameters were estimated by maximum likelihood using Stochastic Approximation Expectation-Maximization (SAEM) algorithm [27].

The basic population PK model included a combination of structural and statistical models. The structural PK models consisted of one- and two-compartment systems with first-order elimination, whereas the statistical PK models consisted of systems where individual PK parameters were assumed to follow log-normal distributions [27] and where exponential random effects were applied for inter-individual variabilities as followed:

$$
\mathrm{Pi}=\mathrm{P} \times \mathrm{e}^{\eta \mathrm{Pi}}
$$

Pi and $\eta^{P i}$ represent the PK parameters of subject $i$ and its individual random effect, respectively. The distribution of $\mathrm{Pi}$ was defined by two components $\mathrm{P}$ and $\omega \mathrm{P}$, which were the typical value of the parameters and the standard deviation of $\eta^{\mathrm{Pi}}$, respectively. Additionally, independent random effects corresponding to a diagonal of the variancecovariance matrix were assumed. The constant, proportional, and combined error models were assessed.

The appropriate basic model was selected based on the Bayesian Information Criterion (BIC) [28], the precision of estimates, and the goodness-of-fit plots. The BIC was calculated as follow $\mathrm{BIC}=-2 \log (\mathrm{L})+\mathrm{k}(\log \mathrm{N})$, in which $\mathrm{L}$ was a likelihood, $\mathrm{k}$ was the total number of parameters (i.e., fixed effects, random effects, and error model parameters) in the model, and $\mathrm{N}$ was the total number of data observations. The model with the lowest BIC was selected [28].

Covariates tested included age, weight, body mass index (BMI), gender, clearance

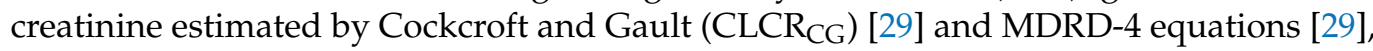
Anthonisen score, respiratory distress, and diuretics intake. The covariates were measured at the time of blood sampling, except for the Anthonisen score, which was recorded on the first day the patient entered the Respiratory Centre. Continuous covariates were log-transformed and centered as followed:

$$
\log \mathrm{COVi}=\log (\mathrm{COVi} / \mathrm{COV} \text { weighted mean })
$$

where COV weighted mean is the mean of the covariate weighted by a number of observations per individual. The covariate and PK parameter relationships were visually investigated in MONOLIX. The selection of covariates was determined using a stepwise approach as described previously [28]. First, the correlation between the covariates and the PK parameters were preliminary evaluated using a visual graph and univariate statistics. The covariates with a $p$-value less than 0.05 were considered for the covariate model. Second, in forward-selection, covariates were added to the model. The covariates with an objective function value (OFV) reduction greater than 6.635 were considered to be significant $(p<0.01)$. Third, in backward elimination, any covariate associated with an OFV increase greater than $10.828(p<0.001)$ was kept in the model [28]. Model adequacy was further evaluated using goodness-of-fit. Observations values were plotted versus individual and population prediction values. The individual weighted residuals (IWRES) and population-weighted residuals (PWRES) were plotted versus predicted concentration plots, and the normalized prediction distribution errors (NPDE) versus time after the dose to evaluate for randomness around the line of unity [28]. The uncertainty of the population parameters of the final model was finally estimated using 1000 bootstrap replicates. The predictive performance of the developed model was examined using a visual predictive check (VPC) plot [28]. 


\subsection{Monte Carlo Simulations and Development of a Therapeutic Algorithm}

Monte Carlo simulations of 1000 patients were applied with different dosing regimens for CAZ and IMI using the final model. CAZ dose of $1 \mathrm{~g} \mathrm{q} 12 \mathrm{~h}, 1 \mathrm{~g} \mathrm{q} 8 \mathrm{~h}, 2 \mathrm{~g} \mathrm{q} 12 \mathrm{~h}$, and $2 \mathrm{~g}$ q8h and IMI dose of $0.5 \mathrm{~g}$ q6h, $0.75 \mathrm{~g}$ q6h, $1 \mathrm{~g}$ q6h, and $1 \mathrm{~g}$ q8h were used in the simulations $[30,31]$. A short-term infusion (SI) of $30 \mathrm{~min}$ and extended infusion (EI) of $3 \mathrm{~h}$ were applied. Continuous infusion (CI) of CAZ and IMI were also examined. CI of CAZ consisted of a loading dose of $2 \mathrm{~g}$ followed by a CI of $6 \mathrm{~g}$ q24h. CI of IMI consisted of a loading dose of $1 \mathrm{~g}$ followed by a CI of $4 \mathrm{~g}$ q24h, renewed every $3 \mathrm{~h}$ due to the rapid degradation of the molecule in solution $[30,31]$. The estimated glomerular filtration rates of $30-60,60-90$, and $>90 \mathrm{~mL} / \mathrm{min}$ were used to stratify the simulations. The fraction of time that free drug concentration remains above Minimum Inhibitory Concentration $(f \mathrm{~T}>\mathrm{MIC})$ was used as the surrogate PK/PD index for both CAZ and IMI. Free concentrations of the drug were assumed using the protein binding values of $14 \%$ for CAZ [32] and 20\% for IMI [33]. The probability of target attainment (PTA) aiming at $40 \% f \mathrm{~T}>\mathrm{MIC}$ for IMI and $60 \% f \mathrm{~T}>\mathrm{MIC}$ [34-36] for CAZ, was estimated at $72 \mathrm{hrs}$ using MIC ranging from 0.125 to $32 \mu \mathrm{g} / \mathrm{mL}$. These PTA were selected as they have previously been associated to significantly reduce treatment failure $[37,38]$. A more aggressive target of $100 \% f \mathrm{~T}>\mathrm{MIC}$ was also examined to cover scenarios where patients present severe conditions [39,40]. P. aeruginosa MIC breakpoints considered for susceptibility (S), intermediate susceptibility (I), and resistance (R) followed the guidance of Clinical \& Laboratory Standards Institute (CLSI) and were $\leq 8 \mathrm{mg} / \mathrm{L}(\mathrm{S}), 16 \mathrm{mg} / \mathrm{L}$ (I) and $\geq 32 \mathrm{mg} / \mathrm{L}$ (R) for CAZ and $\leq 2 \mathrm{mg} / \mathrm{L}$ (S), $4 \mathrm{mg} / \mathrm{L}$ (I) and $\geq 8 \mathrm{mg} / \mathrm{L}$ (R) for IMI [41]. Sufficient antimicrobial effect was assumed if PTA exceeded $90 \%$ (90\% PTA) [42]. The lowest daily dose obtaining $\geq 90 \%$ PTA was considered to be optimal [42]. Three clinical microbiology scenarios were then assumed for dose selection including (1) P. aeruginosa confirmation without susceptibility result or high risk of $P$. aeruginosa infection; (2) $P$. aeruginosa infection with antibiogram result (susceptible, intermediate, and resistant) and (3) P. aeruginosa infection with MIC values known. All simulations were performed using package mlxR (Simulx, RRID:SCR 000486) version 4.1.0 [43] in R 4.0.3 ( $R$ Core Team, 2020).

\section{Results}

\subsection{Demographics}

Key patient demographic and baseline characteristics are summarized in Table 1. A total of 94 patients, 50 receiving CAZ and 44 receiving IMI, were included in the study. Patients between the 2 groups did not present significant demographic differences, except for CLCR $_{\mathrm{CG}}$. Median (interquartile range, IQR) age was 69 yo (63-77) and 65 yo (60-72) for patients in the CAZ and IMI groups, respectively. Median (IQR) of total body weight and free fat masses were $51 \mathrm{~kg}(47-57)$ and $45 \mathrm{~kg}$ (41-47) for patients in the CAZ group, and $50 \mathrm{~kg}(47-55)$ and $43 \mathrm{~kg}(40-46)$ for patients in the IMI group, respectively. The median (IQR) of CLCR $\mathrm{CG}$ was $62.9 \mathrm{~mL} / \mathrm{min}(49.0-76.8)$ for CAZ patients versus $76.6 \mathrm{~mL} / \mathrm{min}$ (57.5-96.6) for IMI patients. In both groups, over $60 \%$ of the patients had a history of COPD, and few ( 2 and $9 \%$ for CAZ and IMI, respectively) had COPD for more than 10 years. Forced expiratory volume (FEV1) values at baseline were available for 23 and 6 patients in CAZ and IMI groups, respectively, and showed that patients had overall poor pulmonary function $(>90 \%$ had FEV1 $<70 \%$ ). A significant number of the patients also presented respiratory distress ( 34 and $66 \%$ in CAZ and IMI groups, respectively) and had invasive ventilation (14 and 30\% in CAZ and IMI groups, respectively). However, no patient required admission to the Intensive Care Unit during the study period. All patients received inhaled and/or systemic bronchodilators. The median antibiotic treatment duration for both drugs was 10 days with a value ranging from 8-13 or 7-14 in the CAZ or IMI group, respectively. Conventional dosing interval and infusion time followed the decision of the physician and the sampling varied accordingly. Dose of $1 \mathrm{~g}$ every $8 \mathrm{~h}$ was used in $38(78 \%)$ patients with CAZ and 24 (55\%) patients with IMI. 
Table 1. Personal and clinical characteristics of patients with acute exacerbations of chronic obstructive pulmonary disease enrolled in the ceftazidime and imipenem cohorts.

\begin{tabular}{|c|c|c|}
\hline Parameters & $\begin{array}{l}\text { Ceftazidime } \\
\quad(n=50)\end{array}$ & $\begin{array}{c}\text { Imipenem } \\
(n=44)\end{array}$ \\
\hline Age (years) & $69(63-77)$ & $65(60-72)$ \\
\hline Male (No., \%) & $47(94)$ & $41(93)$ \\
\hline \multicolumn{3}{|l|}{ History of diagnosis of COPD } \\
\hline$<1$ year (No., \%) & $18(36)$ & $10(23)$ \\
\hline $1-10$ year (No., \%) & $31(62)$ & $30(68)$ \\
\hline$>10$ year $($ No., \%) & $1(2)$ & $4(9)$ \\
\hline Total body weight (kg) & $51(47-57)$ & $50(47-55)$ \\
\hline Height $(\mathrm{cm})$ & $162.5(160-167)$ & $160(159-165)$ \\
\hline Body Mass Index $\left(\mathrm{kg} / \mathrm{m}^{2}\right)$ & $19.49(17.55-21.44)$ & $19.51(18.22-19.51)$ \\
\hline Free Fat Mass (kg) & $45(41-47)$ & $43(40-46)$ \\
\hline \multicolumn{3}{|l|}{ FEV1 a } \\
\hline$<30 \%($ No., $\%)$ & $13 / 23(57)$ & $2 / 6(33)$ \\
\hline $30-50 \%$ (No., \%) & $6 / 23(26)$ & $2 / 6(33)$ \\
\hline $50-70 \%$ (No., \%) & $3 / 23(13)$ & $1 / 6(17)$ \\
\hline >70\% (No., \%) & $1 / 23(4)$ & $1 / 6(17)$ \\
\hline \multicolumn{3}{|l|}{ Anthonisen score $b$} \\
\hline Major (No., \%) & $12(24)$ & $18(41)$ \\
\hline Medium (No., \%) & $27(54)$ & $8(18)$ \\
\hline Minor (No., \%) & $11(22)$ & $18(41)$ \\
\hline Respiratory distress (No., \%) & $17(34)$ & $29(66)$ \\
\hline Invasiveventilation (No., \%) & $7(14)$ & $13(30)$ \\
\hline $\operatorname{CLCR}_{\mathrm{CG}}(\mathrm{mL} / \mathrm{min})$ & $62.9(49.0-76.8)$ & $76.6(57.5-96.6)$ \\
\hline \multicolumn{3}{|l|}{ Concomitantmedication } \\
\hline Diuretic (No., \%) & $9(18)$ & $8(18)$ \\
\hline Systemic corticosteroids (No., \%) & $27(54)$ & $32(73)$ \\
\hline Inhaled corticosteroids (No., \%) & $47(94)$ & $41(93)$ \\
\hline Systemic SABA (No., \%) & $16(32)$ & $16(36)$ \\
\hline Inhaled SABA (No., \%) & $50(100)$ & $41(93)$ \\
\hline SAMA (No., \%) & $43(86)$ & $41(93)$ \\
\hline \multicolumn{3}{|l|}{ Antibiotic regimen } \\
\hline $0.5 \mathrm{~g} \mathrm{q} 12 \mathrm{~h}$ (No., \%) & - & $1(2)$ \\
\hline 0.5 g q8h (No., \%) & - & $4(9)$ \\
\hline $0.5 \mathrm{~g}$ q6h (No., \%) & - & $7(16)$ \\
\hline $1 \mathrm{~g}$ q12h (No., \%) & $1(2)$ & $8(18)$ \\
\hline 1 g q8h (No., \%) & $39(78)$ & $24(55)$ \\
\hline 1 g q6h (No., \%) & $1(2)$ & - \\
\hline 2 g q12h (No., \%) & $3(6)$ & - \\
\hline $2 \mathrm{~g} \mathrm{q} 8 \mathrm{~h}($ No., \%) & $6(12)$ & - \\
\hline Duration of antibiotherapy-(No., days) & $10[8-13]$ & $10[7-14]$ \\
\hline
\end{tabular}

\subsection{Model Building Process}

A total of 97 and 84 plasma samples were obtained from patients using CAZ and IMI, respectively. One sample only was obtained in seven patients (five patients refused the second blood sampling, one patient transferred out after the first blood sample, and one sample could not be collected due to emergency care). The infusion times were different between patients. The concentrations of CAZ and IMI recovered in patient blood samples are presented in Supplemental Figure S1. The result of basic PK model development is presented in Supplemental Table S1. For both drugs, the smallest BIC values (613.47 and 552.06 for CAZ and IMI, respectively) were observed in a one compartmental model with first-order elimination, proportional error, and log-normal parameter distribution. The covariate models derived from the stepwise procedure are presented in Supplemental 
Table S2. No covariate showed a significant impact on the Vd of both drugs. In contrast, the $C_{C C R_{C G}}$ was a significant covariate on the CL of both $C A Z$ and IMI, with a reduction of OFV greatest in comparison to other significant covariates. Adding other covariates did not further significantly improve the OFV.

\subsection{Population Pharmacokinetic Model}

Table 2 summarizes the population PK estimates and bootstrap results for CAZ and IMI in the selected model. The population estimates of the $\mathrm{Vd}$ and CL were $23.7 \mathrm{~L}$ and $8.74 \mathrm{~L} / \mathrm{h}$ for $\mathrm{CAZ}$, and $15.1 \mathrm{~L}$ and $7.88 \mathrm{~L} / \mathrm{h}$ for IMI, respectively. For random effect, the inter-individual variability (IIV) of Vd and CL were $13 \%$ and $20.8 \%$ for CAZ, and $12.9 \%$ and $30 \%$ for IMI, respectively. The correlation between CLCR ${ }_{C G}$ and CL of CAZ and IMI is illustrated in Figure 1. The effect of CLCR ${ }_{C G}$ on CL of CAZ and IMI was as followed: CAZ: $C L i=8.74 \times(\text { CLCRi } / 69.02)^{0.485} \times \mathrm{e}^{\eta \mathrm{CL}} ; \mathrm{IMI}: \mathrm{CLi}=7.88 \times(\mathrm{CLCRi} / 75.54)^{0.532} \times \mathrm{e}^{\eta \mathrm{CL}}$ Bootstrapping results of the 1000 replicates showed marginal differences from respective estimates in the final model (Table 2).

Table 2. Population pharmacokinetic model estimates and bootstrap results for ceftazidime and imipenem after intravenous infusion.

\begin{tabular}{|c|c|c|c|c|c|c|}
\hline \multirow[t]{3}{*}{ Parameters } & \multicolumn{3}{|c|}{ Final Model } & \multicolumn{3}{|c|}{ Bootstrap Results } \\
\hline & \multirow[t]{2}{*}{ Estimates } & \multirow[t]{2}{*}{ RSE (\%) } & \multirow[t]{2}{*}{$p$} & \multirow[t]{2}{*}{ Median } & \multicolumn{2}{|c|}{ 95\% Confidence Interval } \\
\hline & & & & & $2.5 \%$ & $97.5 \%$ \\
\hline \multicolumn{7}{|c|}{ CEFTAZIDIME } \\
\hline $\mathrm{Vd}(\mathrm{L})$ & 23.7 & 2.96 & & 23.98 & 22.361 & 25.66 \\
\hline $\mathrm{CL}(\mathrm{L} / \mathrm{h})$ & 8.74 & 3.18 & & 8.76 & 8.185 & 9.358 \\
\hline$\beta_{\text {CLCRCG on CL }}$ & 0.485 & 17.2 & $2.8 \times 10^{-8}$ & 0.492 & 0.328 & 0.643 \\
\hline$\omega V(\%)$ & 13 & 32 & & 9.55 & 3.9 & 20.1 \\
\hline$\omega \mathrm{CL}(\%)$ & 20.8 & 12.2 & & 19.9 & 14.8 & 24.8 \\
\hline $\mathrm{b}(\%)$ & 12.1 & 16 & & 12.65 & 7.1 & 16.6 \\
\hline \multicolumn{7}{|c|}{ IMIPENEM } \\
\hline $\mathrm{Vd}(\mathrm{L})$ & 15.1 & 6.07 & & 15.17 & 13.318 & 17284 \\
\hline $\mathrm{CL}(\mathrm{L} / \mathrm{h})$ & 7.88 & 5.35 & & 7.91 & 7.117 & 8.771 \\
\hline$\beta_{\text {CLCRCG on CL }}$ & 0.532 & 27.2 & $8.1 \times 10^{-5}$ & 0.54 & 0.163 & 0.949 \\
\hline$\omega \mathrm{V}(\%)$ & 10.7 & 76.4 & & 14.54 & 6.7 & 29.2 \\
\hline$\omega \mathrm{CL}(\%)$ & 29.4 & 12.6 & & 28.75 & 18.9 & 38.1 \\
\hline b (\%) & 23.3 & 12.3 & & 21.3 & 15.6 & 26.8 \\
\hline
\end{tabular}

$V d$, Volume of distribution; $\mathrm{CL}$, Clearance; $\omega \mathrm{V}$, Inter-individual variation in the volume of distribution; $\omega \mathrm{CL}$, Inter-individual variation in the clearance; $b$, Residual variability; $C_{C C R}$, creatinine clearance estimated according to Cockcroft and Gault; $\beta_{C L C R}$ on CL, the regression coefficient of clearance estimated according to $\mathrm{CLCR}_{\mathrm{CG}}$ in log scale.

\subsection{Model Evaluation}

The basic goodness-of-fit plots representing the correlation between observed vs. individual or population predicted concentrations are displayed in Figure 2. Population predicted concentrations showed a good correlation with observed concentrations (correlation coefficients of 0.86 and 0.75 for CAZ and IMI, respectively). Population weighted residuals (PWRES), individual weighted residuals (IWRES), and Normalized Prediction Distribution Error (NDPE) plots showed no significant bias for both drugs as the data equally distributed around the horizontal axis (Supplemental Figure S2). Visual Predictive Check (VPC) plots suggested that the median and 5th and 95th percentiles of observed concentrations were properly predicted by the respective bootstrapped $95 \%$ confident intervals (Figure 3). 
(a)

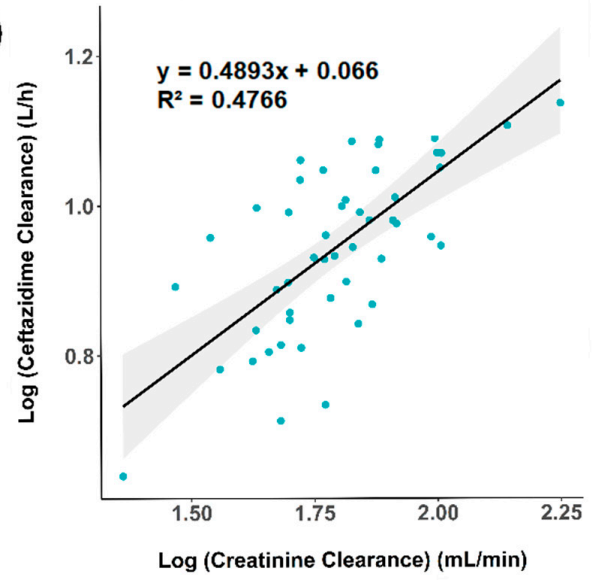

(b)

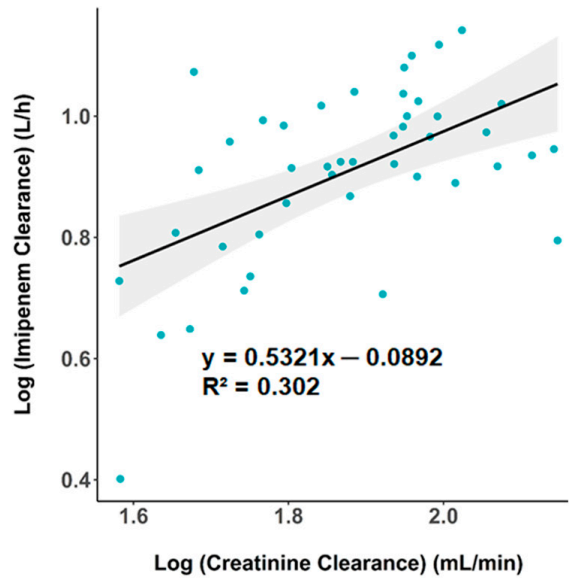

Figure 1. Individual ceftazidime. (a) and imipenem (b) clearance estimates versus creatinine clearance estimated according to Cockcroft and Gault. Log transformed values are plotted, with the solid lines and grey shading areas illustrating the linear regression and the $95 \%$ confident interval, respectively. The regression equations and respective correlation coefficients $\left(R^{2}\right)$ are presented for each plot. Creatinine clearance were estimated by Cockcroft and Gault equation (CLCR $\mathrm{CG}_{\text {) }}$.

(a)

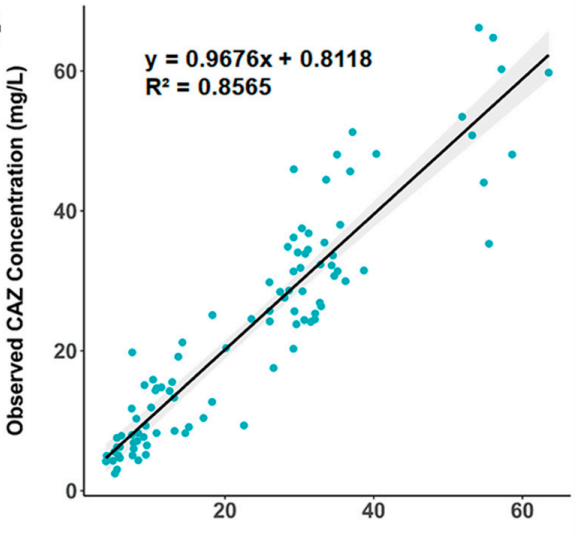

Population Prediction CAZ Concentration (mg/L)

(c)

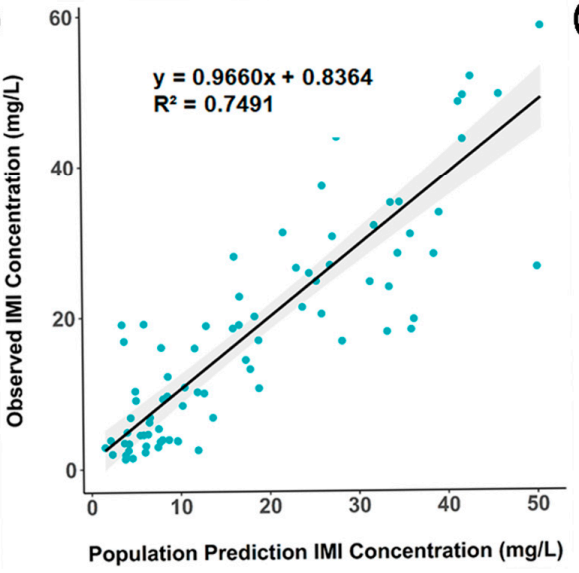

(b)

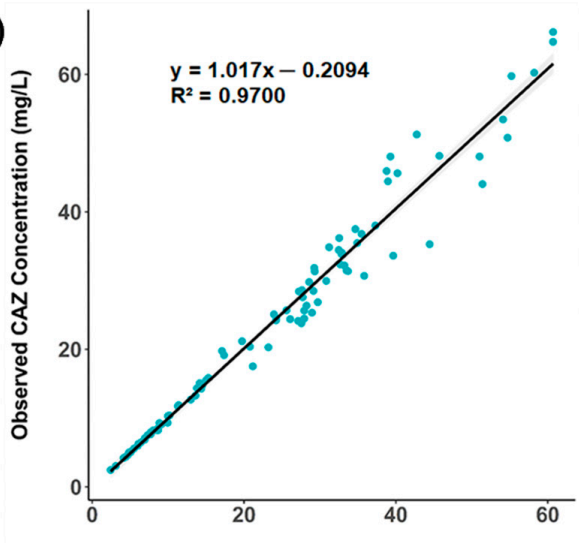

Individual Prediction CAZ Concentration (mg/L)

(d)

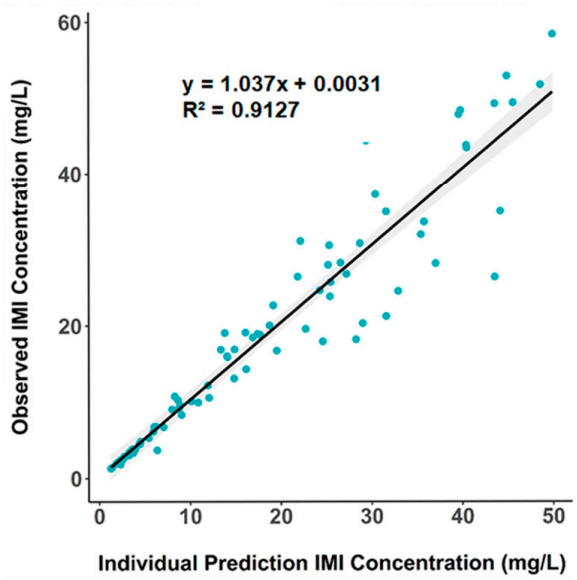

Figure 2. Basic goodness-of-fit plots from the final covariate model. (a,b) Measured ceftazidime (CAZ) concentrations are plotted against the population (a) or the individually-fitted (b) concentrations. (c,d) Measured imipenem (IMI) concentrations are plotted against the population (c) or the individually-fitted (d) concentrations. The solid lines represent linear regression lines with shade areas illustrating the $95 \%$ confident intervals. The regression equations and respective correlation coefficients $\left(\mathrm{R}^{2}\right)$ are presented. 

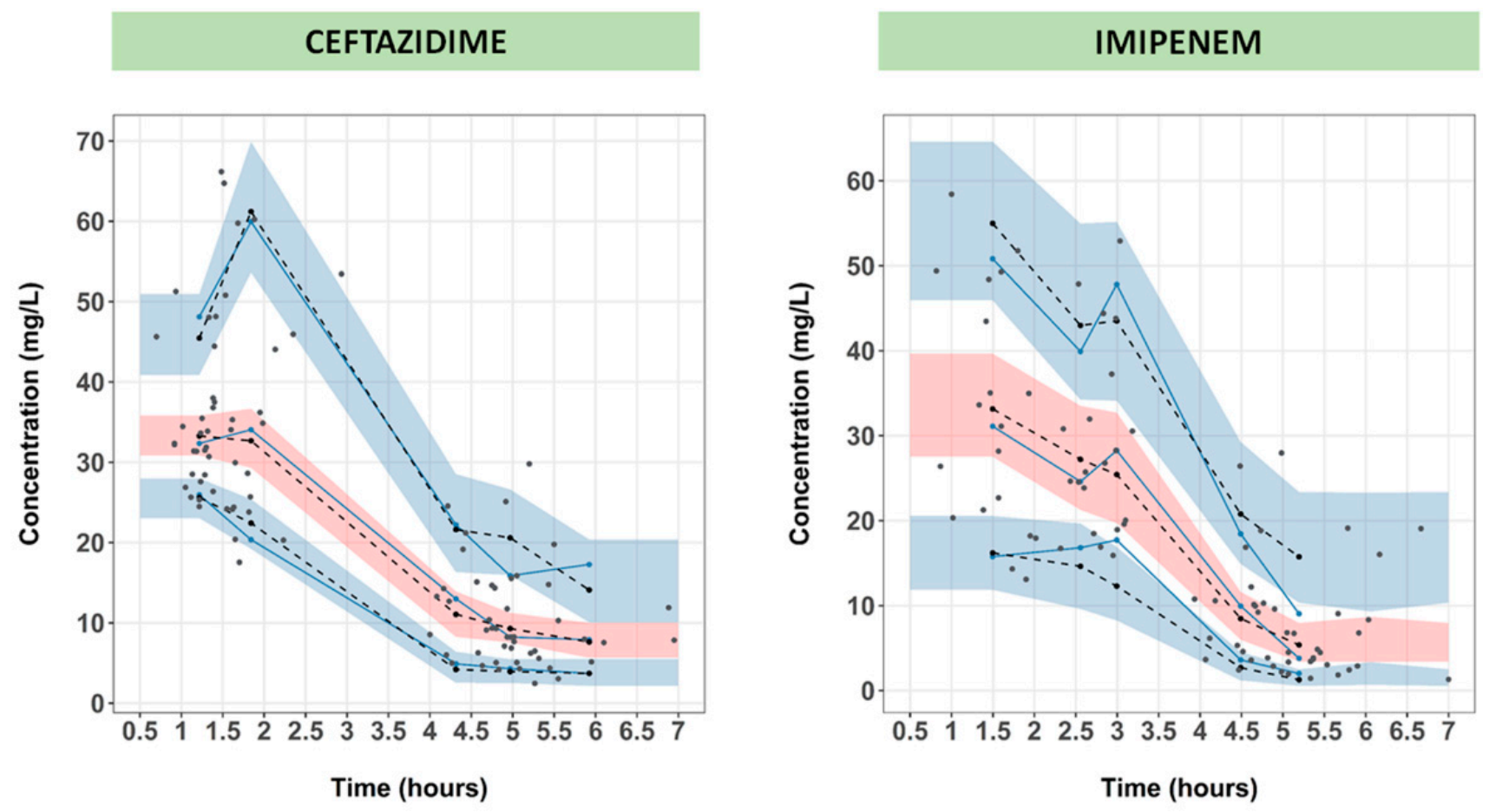

Figure 3. Visual Predictive Check plot versus time. The grey solid lines indicate the 10th, 50th, and 90th percentiles of the observed data. The grey-black dashed lines indicate the 10th, 50th, and 90th percentiles of simulated data. The shaded grey and pink areas represent $90 \%$ prediction intervals from the corresponding percentiles as predicted by the model.

\subsection{Monte Carlo Simulations and Dosing Regimen Recommendations}

Figure 4, Supplemental Tables S3 and S4 illustrate PTA values for various CAZ and IMI dose regimens using targets of $60-100 \% f \mathrm{~T}>\mathrm{MIC}$ for CAZ and $40-100 \% f \mathrm{~T}>\mathrm{MIC}$ for IMI. Simulations were performed and analyzed based on patient renal function. For both drugs, no practical dose covered highly resistant pathogens with MIC equal or greater than $32 \mathrm{mg} / \mathrm{L}$. Patients with good renal function (ie CLCR $\mathrm{CG}>90 \mathrm{~mL} / \mathrm{min}$ ) might not reach the threshold of $90 \%$ PTA on pathogens exhibiting high MIC values, especially when low dose and short infusion were applied. For CAZ, CI showed improved PTA compared to EI. For both drugs, SI (30 $\mathrm{min}$ ) appeared inferior to EI and CI, so it was not further considered.

Based on the results of our simulations and the selection of our model, three microbiological scenarios were assumed to find the most appropriate dosing strategy when P. aeruginosa infection is suspected and targeted. Figure 5 and Supplemental Figure S3 illustrate 2 dosing algorithms depicted from our simulations based on the susceptibility profile of the pathogen. For CAZ, regimens using CI were required to cover pathogens with intermediate resistance. When targeting $100 \% f \mathrm{~T}>\mathrm{MIC}$, prolonged infusion (either EI or CI) increased the chance to obtain $90 \%$ of PTA for both CAZ and IMI. (Supplemental Tables S3 and S4 and Figure S3). Daily doses of $6 \mathrm{~g} \mathrm{CAZ} \mathrm{or} 4 \mathrm{~g} \mathrm{IMI}$ as CI were required to cover most of the susceptible strains. For intermediate resistant and even pathogens with MIC of $8 \mathrm{mg} / \mathrm{L}$, IMI daily dose of $4 \mathrm{~g}$ as CI was likely sufficient. No clinical dose of CAZ, even in CI, could cover pathogens with intermediate resistance (Supplemental Tables S3 and S4 and Figure S3). 

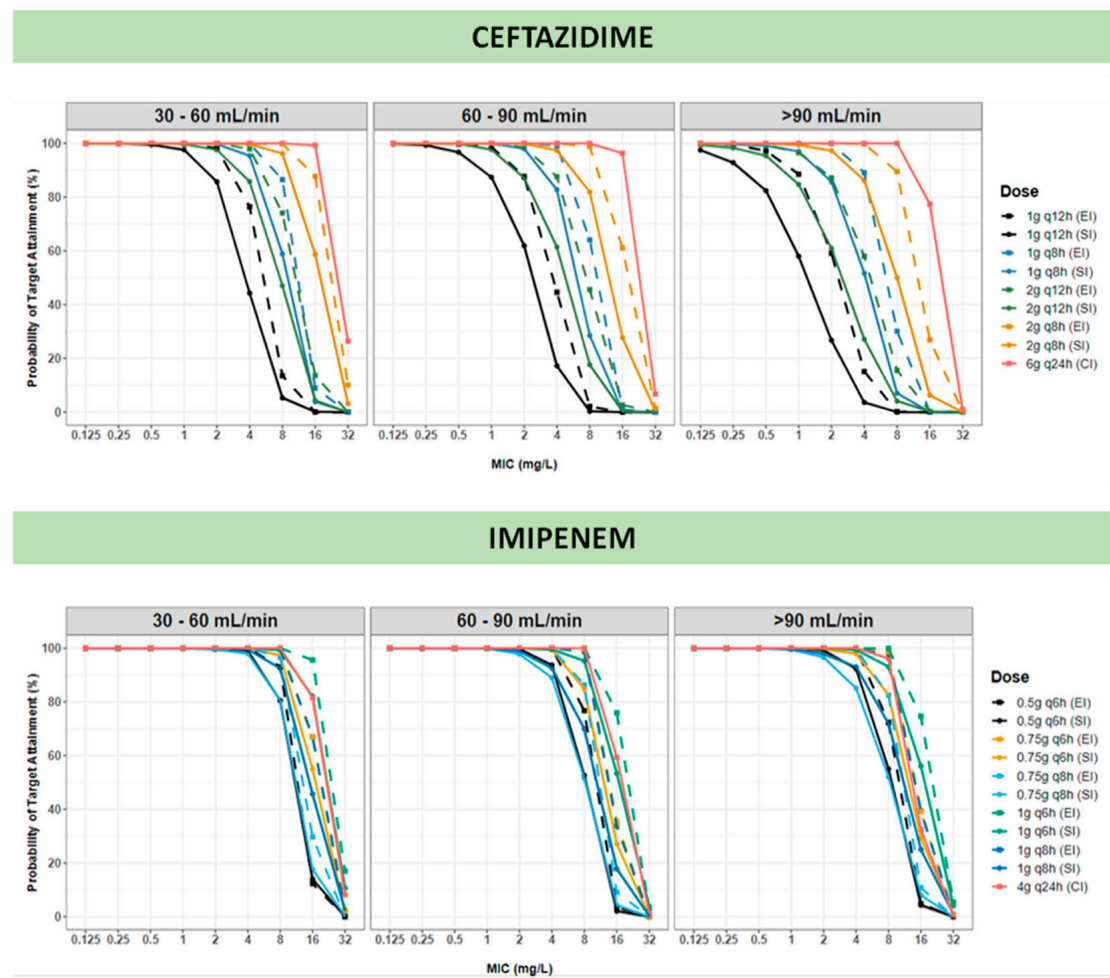

Figure 4. Probability of target attainment (PTA) of ceftazidime with a target of $60 \% f \mathrm{~T}>\mathrm{MIC}$ and imipenem with $40 \%$ $f \mathrm{~T}>\mathrm{MIC}$. MIC values based on the recommendation of Clinical and Laboratory Standards Institute 2020 (CLSI 2020); Dose regimens using short-term infusion (SI: $0.5 \mathrm{~h}$ ), extended infusion (EI: $3 \mathrm{~h}$ ), and continuous infusion $(\mathrm{CI})$ are simulated. The simulations were stratified based on CLCR $\mathrm{CG}$.

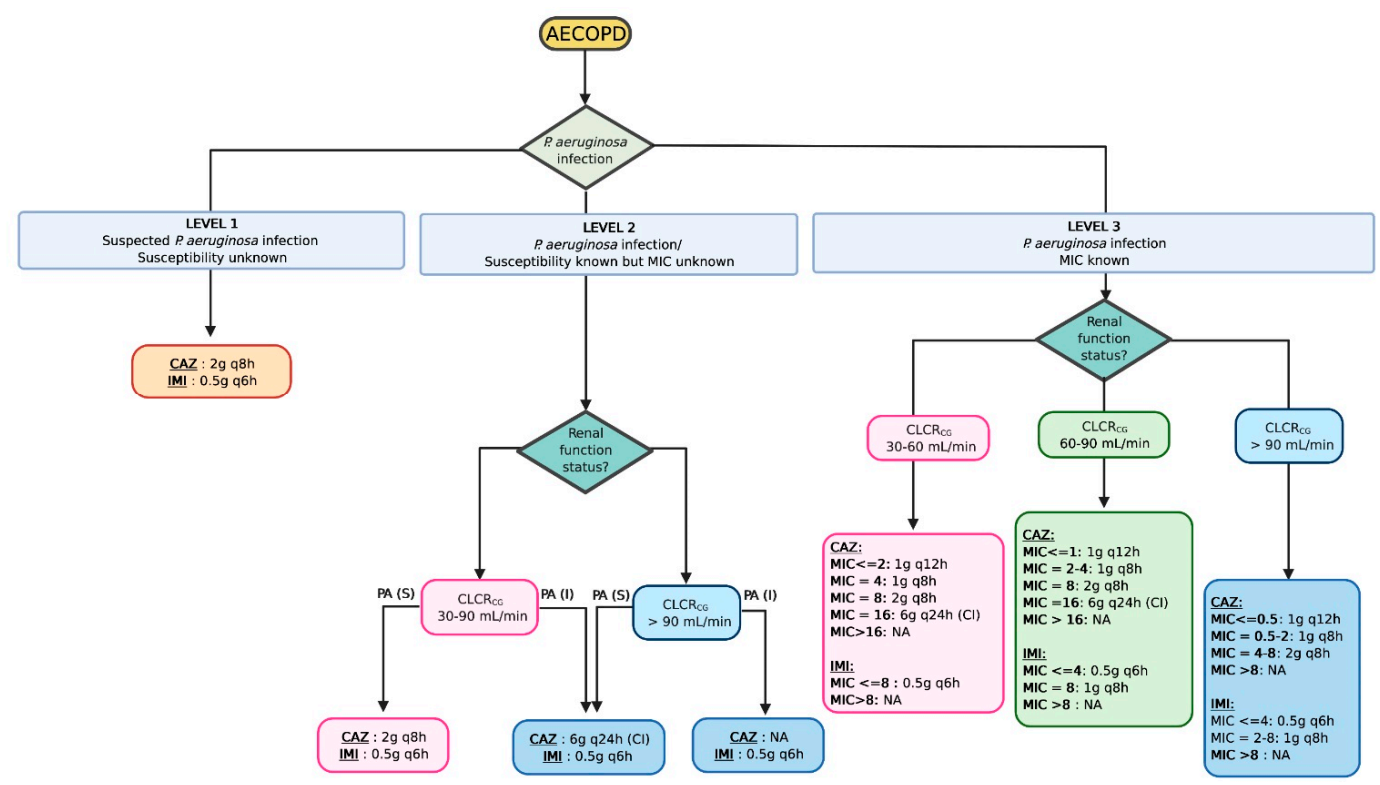

Figure 5. Proposed dosing algorithm based on the simulation results of ceftazidime and imipenem in Acute Exacerbation of Chronic Obstructive Pulmonary Disease (AECOPD) to achieve $60 \% f \mathrm{~T}>\mathrm{MIC}$ for ceftazidime and $40 \% f \mathrm{~T}>\mathrm{MIC}$ for imipenem. MIC: Minimum inhibitory concentration, PA: Pseudomonas aeruginosa, (S): Susceptible; (I): Intermediate resistance, IMI, imipenem; CFZ, ceftazidime; CLCR $_{C G}$, Clearance creatinine according to Cockcroft and Gault equation; q6h, q8h, and q12h, dose following $3 \mathrm{~h}$ extended infusion with dose interval of 6,8 , or $12 \mathrm{~h}$, respectively; CI, continuous infusion. Created with Biorender.com (accessed on 1 February 2021). 


\section{Discussion}

The use of antimicrobial agents to treat AECOPD remains controversial and challenging $[1,6,11-16]$. Since acute exacerbations are triggered by viral multiple factors including viral, bacterial infections, or non-infectious causes, the benefit of antimicrobial treatment remains unclear and subject of debate [44]. However, when the presence of P. aeruginosa is suspected or confirmed in the patient sputum or the patient presents severe dyspnea, guidelines recommend the use of antimicrobials, the selection of which varies depending on local epidemiology $[1,6]$. A recent meta-analysis suggested that using antibiotics, especially targeting $P$. aeruginosa, reduces the treatment failure and shortens the hospital length of stay of patients with AECOPD [41,45]. In Vietnam, CAZ and IMI are routinely used as they have proven to retain efficacy against the local strains of P. aeruginosa [23]. However, concerns are rising towards their proper use to preserve their efficacy and prevent the emergence of resistance. Pathophysiological and clinical factors related to COPD might affect PK profiles of antimicrobials; hence an inappropriate dosing regimen could result in treatment failure, increased emergence of resistance, and higher mortality [19]. Designing an adapted dosing regimen, optimized for specific populations, especially critically-ill patients such as those presenting AECOPD, remains crucial. To the best of our knowledge, this study is the first one to model and simulate CAZ and IMI PKs to explore optimal dosage regimens in patients presenting AECOPD.

In the context of our study, which included 50 and 44 patients in CAZ and IMI groups, respectively, a one-compartment model with first-order elimination, proportional error model with $\mathrm{CLCR}_{\mathrm{CG}}$ as a covariate on clearance provided a superior fit to the data. This result is consistent with previous works published in cystic fibrosis $(\mathrm{CF})$ and critically-ill patients [46,47]. In this study, the Vd of CAZ was $23.7 \mathrm{~L}$. This is comparable with that observed in patients with nosocomial pneumonia (Vd of 23.1 L) [48], and only marginally larger than what is reported in the healthy population (15-20 L) [49]. Similarly, CAZ CL was $8.74 \mathrm{~L} / \mathrm{h}$ in this study versus $6.47 \mathrm{~L} / \mathrm{h}$ in patients with nosocomial pneumonia [48] or $8.57 \mathrm{~L} / \mathrm{h}$ in CF patients [49]. These values are also in line with the CL reported in healthy volunteers $(8.77 \mathrm{~L} / \mathrm{h})[46]$, suggesting that the renal function rather than other covariates might predict the elimination of CAZ observations were confirmed in the covariate model where CLCR $_{C G}$ was the only covariate showing a linear relationship with CL of CAZ when $\log$ transforming both sides of the equation (correlation coefficient 0.4766 ). This finding was also observed in critically-ill patients [48,50]. For IMI, the estimated Vd was $15.1 \mathrm{~L}$ in this study, a value comparable with that observed in a pooled population (15.8 L) [33], whereas larger $\mathrm{Vd}$ were reported in ventilator-associated pneumonia patients $(20.4 \mathrm{~L})$ [51], or sepsis patients with a high burden of IV fluid (Vd 29.9 L) [52]. IMI CL in this study was $7.88 \mathrm{~L} / \mathrm{h}$ versus $13.2 \mathrm{~L} / \mathrm{h}$ in VAP patients [51]. However, similar to CAZ, CLCR $\mathrm{CG}$ also had a significant impact on IMI CL (correlation coefficient of 0.302).

Consistent with the literature, our results confirm that CAZ and IMI elimination is significantly impacted by patients' renal function (OFV reduction of 26.26 and 11.89 for CAZ and IMI, respectively) [33,48,50,51]. To acknowledge this observation, we further explored dose optimization and designed dosing recommendations stratified according to CLCR $_{C G}$. It should be noted that most COPD patients were elderly with chronic conditions, and therefore the chance of augmented renal clearance was low [53]. Therefore, the use of high doses as recommended in other critically ill patients with sepsis should be taken cautiously [54]. We performed simulations with conventional daily doses of 2 to $6 \mathrm{~g}$ for CAZ and 2 to $4 \mathrm{~g}$ for IMI. Higher doses of CAZ ( $\mathrm{g}$ q8h and $3 \mathrm{~h} \mathrm{EI}$ ) were also applied to increase the likelihood to cover P. aeruginosa strains with reduced susceptibility [55]. According to CLSI, CAZ intermediate resistant $P$. aeruginosa exhibits a MIC value of $16 \mathrm{mg} / \mathrm{L}$. Based on our study, no practical dose could reach the target of $60-100 \% f \mathrm{~T}>\mathrm{MIC}$ for patients with normal renal function when intermediate resistance was involved. However, a daily dose of $6 \mathrm{~g}$ administered in $\mathrm{CI}$ could reach the target $>60 \% \mathrm{fT}>\mathrm{MIC}$ for patients with impaired renal function and intermediate resistant isolates. In any case, no simulation was able to cover resistant strains with MIC greater than $16 \mathrm{mg} / \mathrm{L}$, and different treatment strategy 
including other antibiotics should be considered in such cases [56]. In contrast, for IMI the target of $40 \% f \mathrm{~T}>\mathrm{MIC}$ could be achieved with a dose as low as $0.5 \mathrm{~g}$ q6h EI for susceptible pathogens, and $4 \mathrm{~g}$ q24h for a pathogen with a MIC equal or greater than $8 \mathrm{mg} / \mathrm{L}$ when the patient had normal renal function. Therefore, the dose of $1 \mathrm{~g} \mathrm{q} 8 \mathrm{~h}$ previously suggested to cover MDR P. aeruginosa might not be appropriated for all situations [55]. A more aggressive target of $100 \% f \mathrm{~T}>\mathrm{MIC}$ was also investigated as it is sometimes suggested for critically-ill patients [39]. In this study, we show that to achieve such PTA, a dose of $4 \mathrm{~g}$ q24h administered as CI is required (Supplemental Figure S4). Unlike intermittent infusion, CI in critically ill patients allows for antibiotic concentration to remain plateau [57] hence making it easier to attain the target of $100 \% f \mathrm{~T}>\mathrm{MIC}$ and cover susceptible pathogens. However, in the case of pathogens with reduced susceptibility, when using CI and a low dose of antibiotic, the concentration might never reach the MIC level, increasing, therefore, the risk of treatment failure and emergence of resistance [31]. To address that, our algorithm uses only CI with a high dose of antibiotics. This represents a challenge in practice since IMI is poorly stable in aqueous fluid requiring therefore regular renewal of the infusion fluid [58]. IMI CI might be considered when patients present severe clinical conditions or resistant pathogens are suspected and no other treatment options are available [31].

The use of CAZ and IMI is common in medical settings like our hospital [22,23]. As observed in this study, the dose, dose interval, and infusion time vary greatly between patients with no clear recommendation to guide our physicians. There is therefore a possibility of under-dosing patients, increasing the risk of treatment failure, prolonged hospital stay, mortality, and promoting the emergence of resistance, an issue that our hospital is already facing [59]. To better understand the role played by antibiotics in the management of AECOPD, further research including PK/PD modeling and Monte Carlo simulations are much warranted [60]. This is the first study to provide insights towards a better understanding of the impact of dose and dose interval on the predicted efficacy of IMI and CAZ in patients with AECOPD. This study carries, however, several limitations, that may to a certain extent impact the results. First, due to cultural challenges related to blood sampling for research purposes, the PK study was performed with a sparse sampling strategy. This may affect the precision of the developed population pharmacokinetic models [61]. However, our PK models were relatively comparable with other published ones, suggesting the appropriateness for dose simulation. Second, patients included in our study present smaller sizes and lower weights compared to the Caucasian population. This should be taken into consideration for future extrapolation of the data to caucasian patients and future PK/PD studies should be required to confirm our finding. Third, CLCR $_{C G}$ was calculated to estimate the patient's renal function, instead of using timed urine collection. We believe that the bias it may have induced in our study is only marginal as our population did not include critically severe patients. However, further studies in critically ill patients should consider the benefit of using timed urine collection. Last, due to the lack of sufficient MIC data of pathogens isolated from COPD patients in our hospital, we were not able to translate and compare our findings with the current local practices. We have therefore used the CLSI classification to examine the chance of attaining the PK/PD target. The empirical doses in the proposed algorithm derived from our simulations were applied for pathogens with MIC below the susceptible breakpoint, and the chance to cover pathogens in actual patients may be different.

\section{Conclusions}

Our study described PK characteristics of CAZ and IMI, two of the most commonly used anti-Pseudomonas beta-lactams, in hospitalized COPD patients presenting acute exacerbation. We propose a dosing algorithm in which we highlight the use of high-dose CAZ for suspected P. aeruginosa with reduced susceptibility. Additional studies are warranted to validate our proposed dosing algorithm and to make it applicable in clinical practice. 
Supplementary Materials: The following are available online at https://www.mdpi.com/article/10 .3390 / pharmaceutics13040456/s1, Table S1. Selection steps for basic population pharmacokinetic models of ceftazidime and imipenem in our cohorts of patients with acute exacerbations of chronic obstructive pulmonary disease, Table S2. Selection steps for covariates models of ceftazidime and imipenem in our cohorts of patients with acute exacerbations of chronic obstructive pulmonary disease, Table S3. Probability of target attainment (PTA) of ceftazidime administrated as a short-term, extended, and continuous infusion, Table S4. Probability of target attainment (PTA) of imipenem administrated as a short-term, extended, and continuous infusion, Figure S1. Spaghetti plot illustrating ceftazidime (a) and imipenem (b) concentrations versus time, Figure S2. Goodness-of-fit plots of the final model with covariates for ceftazidime and imipenem, Figure S3. Visual Predictive Check plot versus time, Figure S4. Proposed dosing algorithm based on simulation result of ceftazidime and imipenem treatments in Acute Exacerbation of Chronic Obstructive Pulmonary Disease (AECOPD) to obtain $100 \% f$ T $>$ MIC.

Author Contributions: Conceptualization, T.-M.N., T.-H.N., D.-H.V., H.-A.N., F.V.B. and C.V.; methodology, T.-M.N., T.-H.N., D.-H.V., D.-C.L., N.-B.V., T.-N.C., H.-A.N., T.-P.P., F.V.B., C.V. and Q.-C.N.; software, T.-H.N., A.-Q.T. and C.V.; validation, T.-H.N., A.-Q.T. and D.-H.V.; formal analysis, T.-H.N., A.-Q.T., D.-H.V., C.V. and H.-A.N.; investigation, T.-M.N., T.-H.N., D.-C.L. and N.-B.V.; resources, D.-C.L., N.-B.V., T.-N.C., T.-P.P. and Q.-C.N.; Data curation, T.-H.N., A.-Q.T. and D.-H.V.; writing-original draft preparation, T.-M.N., T.-H.N., D.-H.V., D.-C.L., N.-B.V. and C.V.; writing-review and editing, A.-Q.T., T.-N.C., H.-A.N., T.-P.P., F.V.B., C.V. and Q.-C.N.; visualization, T.-H.N., A.-Q.T., D.-H.V. and C.V.; supervision, H.-A.N., T.-P.P., F.V.B., C.V. and Q.-C.N.; project administration, T.-M.N., T.-H.N. and D.-H.V.; funding acquisition, D.-H.V. and Q.-C.N. All authors have read and agreed to the published version of the manuscript.

Funding: This study has been supported by the internal institution fund of Bach Mai hospital and Hanoi University of Pharmacy.

Institutional Review Board Statement: The study was conducted according to the guidelines of the Declaration of Helsinki and approved by the Institutional Review Board (or Ethics Committee) of Bach Mai hospital (reference \# 2919/QD-BM for the protocol BM-2017-957-50, approval date on 26 December 2017).

Informed Consent Statement: Informed consent was obtained from all subjects involved in the study.

Data Availability Statement: Not applicable.

Acknowledgments: The authors appreciate all patients participating in this study. We express our gratitude to Paul M. Tulkens, Louvain Drug Research Institute, Université catholique de Louvain, who provided valuable ideas and guidance. We would like to thank Lixsoft (Batiment D, Antony, France) for supporting the academic license and guidance for this work.

Conflicts of Interest: The authors declare no conflict of interest.

\section{References}

1. Global Initiative for Chronic Obstructive Lung Disease, GOLD Report 2020. Available online: https://goldcopd.org/wp-content/ uploads/2019/12/GOLD-2020-FINAL-ver1.2-03Dec19_WMV.pdf (accessed on 13 February 2021).

2. Quaderi, S.A.; Hurst, J.R. The unmet global burden of COPD. Glob. Health Epidemiol. 2018, 3, e4. [CrossRef] [PubMed]

3. Rabe, K.F.; Watz, H. Chronic obstructive pulmonary disease. Lancet 2017, 389, 1931-1940. [CrossRef]

4. Lâm, H.T.; Ekerljung, L.; Tu·ò·ng, N.V.; Rönmark, E.; Larsson, K.; Lundbäck, B. Prevalence of COPD by disease severity in men and women in Northern Vietnam. COPD J. Chronic Obstr. Pulm. Dis. 2014, 11, 575-581. [CrossRef]

5. Châu, N.Q. Situation of Diagnosis and Treatment of Chronic Obstructive Pulmonary Disease at the Centre of Respiratory of Bach Mai Hospital in the Period of 5 Years 1996-2000 (Full-Text in Vietnamese); Medical Publishing House: Hanoi, Vietnam, 2002; Volume 17, pp. 50-58.

6. Zeki, A.A.; Schivo, M.; Chan, A.; Albertson, T.E.; Louie, S. The Asthma-COPD Overlap Syndrome: A common clinical problem in the elderly. J. Allergy 2011, 2011, 1-10. [CrossRef]

7. Zamzam, M.A.; Azab, N.Y.; El Wahsh, R.A.; Ragab, A.Z.; Allam, E.M. Quality of life in COPD patients. Egypt. J. Chest Dis. Tuberc. 2012, 61, 281-289. [CrossRef]

8. Mantero, M.; Rogliani, P.; Di Pasquale, M.; Polverino, E.; Crisafulli, E.; Guerrero, M.; Gramegna, A.; Cazzola, M.; Blasi, F. Acute exacerbations of COPD: Risk factors for failure and relapse. Int. J. Chronic Obs. Pulm. Dis. 2017, 12, 2687-2693. [CrossRef]

9. Müllerova, H.; Maselli, D.J.; Locantore, N.; Vestbo, J.; Hurst, J.R.; Wedzicha, J.A.; Bakke, P.; Agusti, A.; Anzueto, A. Hospitalized Exacerbations of COPD: Risk factors and outcomes in the ECLIPSE cohort. Chest 2015, 147, 999-1007. [CrossRef] [PubMed] 
10. Guerrero, M.; Crisafulli, E.; Liapikou, A.; Huerta, A.; Gabarrús, A.; Chetta, A.; Soler, N.; Torres, A. Readmission for acute exacerbation within 30 days of discharge is associated with a subsequent progressive increase in mortality risk in COPD patients: A long-term observational study. PLoS ONE 2016, 11, e0150737. [CrossRef]

11. Tiew, P.Y.; Jaggi, T.K.; Chan, L.L.Y.; Chotirmall, S.H. The airway microbiome in COPD, bronchiectasis and bronchiectasis-COPD overlap. Clin. Respir. J. 2021, 15, 123-133. [CrossRef]

12. Dixit, D.; Bridgeman, M.B.; Madduri, R.P.; Kumar, S.T.; Cawley, M.J. Pharmacological management and prevention of exacerbations of chronic obstructive pulmonary disease in hospitalized patients. $P$ T 2016, 41, 703-712.

13. Sapey, E.; Stockley, R.A. COPD exacerbations. 2: Aetiology. Thorax 2006, 61, 250-258. [CrossRef] [PubMed]

14. Erkan, L.; Uzun, O.; Findik, S.; Katar, D.; Sanic, A.; Atici, A.G. Role of bacteria in acute exacerbations of chronic obstructive pulmonary disease. Int. J. Chronic Obs. Pulm. Dis. 2008, 3, 463-467. [CrossRef]

15. Groenewegen, K.H.; Wouters, E.F.M. Bacterial infections in patients requiring admission for an acute exacerbation of COPD; a 1-year prospective study. Respir. Med. 2003, 97, 770-777. [CrossRef]

16. Roede, B.M.; Bresser, P.; Bindels, P.J.E.; Kok, A.; Prins, M.; Riet, G.T.; Geskus, R.B.; Herings, R.M.C.; Prins, J.M. Antibiotic treatment is associated with reduced risk of a subsequent exacerbation in obstructive lung disease: An historical population based cohort study. Thorax 2008, 63, 968-973. [CrossRef] [PubMed]

17. Domenech, A.; Puig, C.; Martí, S.; Santos, S.; Fernández, A.; Calatayud, L.; Dorca, J.; Ardanuy, C.; Liñares, J. Infectious etiology of acute exacerbations in severe COPD patients. J. Infect. 2013, 67, 516-523. [CrossRef] [PubMed]

18. Garcia-Vidal, C.; Almagro, P.; Romani, V.; Rodriguez-Carballeira, M.; Cuchi, E.; Canales, L.; Blasco, D.; Heredia, J.L.; Garau, J. Pseudomonas aeruginosa in patients hospitalised for COPD exacerbation: A prospective study. Eur. Respir. J. 2009, 34, 1072-1078. [CrossRef] [PubMed]

19. Eklöf, J.; Sørensen, R.; Ingebrigtsen, T.S.; Sivapalan, P.; Achir, I.; Boel, J.B.; Bangsborg, J.; Ostergaard, C.; Dessau, R.B.; Jensen, U.S.; et al. Pseudomonas aeruginosa and risk of death and exacerbations in patients with chronic obstructive pulmonary disease: An observational cohort study of 22053 patients. Clin. Microbiol. Infect. 2020, 26, 227-234. [CrossRef] [PubMed]

20. Choi, J.; Oh, J.Y.; Lee, Y.S.; Hur, G.Y.; Lee, S.Y.; Shim, J.J.; Kang, K.H.; Min, K.H. Pseudomonas aeruginosa infection increases the readmission rate of COPD patients. COPD 2018, 13, 3077-3083. [CrossRef]

21. Planquette, B.; Peron, J.; Dubuisson, E.; Roujansky, A.; Laurent, V.; Legriel, S.; Ferre, A.; Bruneel, F.; Bedos, J.P.; Le Monnier, A.; et al. Antibiotics against pseudomonas aeruginosa for COPD exacerbation in ICU: A 10-year retrospective study. COPD 2015, 379. [CrossRef] [PubMed]

22. Minh, N.T.; Hường, T.T. Analysis of actual use of antibiotics for acute exacerbation of chronic obstructive pulmonary disease in the respiratory center of bach mai hospital (Ha Noi) (Full-Text in Vietnamese). Pharm. J. (Tap Duoc) 2019, 59, 3-8.

23. Thắng, N.M. Study on Clinical and Microbiological Characteristics in the Exacerbation of Chronic Obstructive Pulmonary Disease at Respiratory Center, Bach Mai Hospital (Ha Noi) (Full-Text in Vietnamese). Master's Thesis, Hanoi Medical University, Hanoi, Vietnam, 2017.

24. Tängdén, T.; Ramos Martín, V.; Felton, T.W.; Nielsen, E.I.; Marchand, S.; Brüggemann, R.J.; Bulitta, J.B.; Bassetti, M.; Theuretzbacher, U.; Tsuji, B.T.; et al. The role of infection models and PK/PD modelling for optimising care of critically ill patients with severe infections. Intensive Care Med. 2017, 43, 1021-1032. [CrossRef]

25. Chi, L.Đ. Development of HPLC method for assay of ceftazidime in Plasma (Full-Text in Vietnamese). Pharm. J. (Tap Duoc) 2018, 501, 71-74.

26. Chi, L.Đ. Development of HPLC Method for assay of imipenem and meropenem in Plasma (Full-text in Vietnamese). Pharm. J. (Tap Duoc) 2017, 500, 46-49.

27. Traynard, P.; Ayral, G.; Twarogowska, M.; Chauvin, J. Efficient pharmacokinetic modeling workflow with the Monolixsuite: A case study of remifentanil. CPT Pharmacomet. Syst. Pharmacol. 2020, 9, 198-210. [CrossRef]

28. Mould, D.; Upton, R. Basic concepts in population modeling, simulation, and model-based drug development-part 2: Introduction to pharmacokinetic modeling methods. Cpt Pharmacomet. Syst. Pharmacol. 2013, 2, 38. [CrossRef]

29. Willems, J.M.; Vlasveld, T.; den Elzen, W.P.; Westendorp, R.G.; Rabelink, T.J.; de Craen, A.J.; Blauw, G.J. Performance of CockcroftGault, MDRD, and CKD-EPI in estimating prevalence of renal function and predicting survival in the oldest old. BMC Geriatr. 2013, 13, 113. [CrossRef] [PubMed]

30. Electronic Medicines Compendium (Emc) Ceftazidime 1g Powder for Solution for Injection-Summary of Product Characteristics (SmPC)-(Emc). Available online: https://www.medicines.org.uk/emc/product/6346/smpc (accessed on 27 February 2021).

31. Suchánková, H.; Lipš, M.; Urbánek, K.; Neely, M.N.; Strojil, J. Is continuous infusion of imipenem always the best choice? Int. J. Antimicrob. Agents 2017, 49, 348-354. [CrossRef]

32. LeBel, M.; Barbeau, G.; Vallee, F.; Bergeron, M.G. Pharmacokinetics of ceftazidime in elderly volunteers. Antimicrob. Agents Chemother. 1985, 28, 713-715. [CrossRef]

33. Van Hasselt, J.G.C.; Rizk, M.L.; Lala, M.; Chavez-Eng, C.; Visser, S.A.G.; Kerbusch, T.; Danhof, M.; Rao, G.; van der Graaf, P.H. Pooled population pharmacokinetic model of imipenem in plasma and the lung epithelial lining fluid: Imipenem Pharmacokinetics in Lung and Plasma. Br. J. Clin. Pharmacol. 2016, 81, 1113-1123. [CrossRef]

34. Keel, R.A.; Kuti, J.L.; Sahm, D.F.; Nicolau, D.P. Pharmacodynamic evaluation of i.v. antimicrobials against pseudomonas aeruginosa samples collected from U.S. hospitals. Am. J. Health Syst. Pharmacol. 2011, 68, 1619-1625. [CrossRef] 
35. Eagye, K.J.; Banevicius, M.A.; Nicolau, D.P. Pseudomonas aeruginosa is not just in the intensive care unit any more: Implications for empirical therapy. Crit. Care Med. 2012, 40, 1329-1332. [CrossRef] [PubMed]

36. Drusano, G.L. Antimicrobial pharmacodynamics: Critical interactions of "bug and drug". Nat. Rev. Microbiol. 2004, 2, 289-300. [CrossRef] [PubMed]

37. Sakka, S.G.; Glauner, A.K.; Bulitta, J.B.; Kinzig-Schippers, M.; Pfister, W.; Drusano, G.L.; Sörgel, F. Population pharmacokinetics and pharmacodynamics of continuous versus short-term infusion of imipenem-cilastatin in critically ill patients in a randomized, controlled trial. Antimicrob. Agents Chemother. 2007, 51, 3304-3310. [CrossRef] [PubMed]

38. Crandon, J.L.; Bulik, C.C.; Kuti, J.L.; Nicolau, D.P. Clinical pharmacodynamics of cefepime in patients infected with pseudomonas aeruginosa. Antimicrob. Agents Chemother. 2010, 54, 1111-1116. [CrossRef] [PubMed]

39. Zelenitsky, S.A.; Ariano, R.E.; Zhanel, G.G. Pharmacodynamics of empirical antibiotic monotherapies for an intensive care unit (ICU) population based on canadian surveillance data. J. Antimicrob. Chemother. 2011, 66, 343-349. [CrossRef]

40. McKinnon, P.S.; Paladino, J.A.; Schentag, J.J. Evaluation of area under the Inhibitory Curve (AUIC) and time above the minimum inhibitory concentration ( $>\mathrm{MIC}$ ) as predictors of outcome for cefepime and ceftazidime in serious bacterial infections. Int. J. Antimicrob. Agents 2008, 31, 345-351. [CrossRef] [PubMed]

41. Vollenweider, D.J.; Frei, A.; Steurer-Stey, C.A.; Garcia-Aymerich, J.; Puhan, M.A. Antibiotics for exacerbations of chronic obstructive pulmonary disease. Cochrane Database Syst. Rev. 2018, 10, CD010257. [CrossRef] [PubMed]

42. Europe Medicine Agency. Guideline on the Use of Pharmacokinetics and Pharmacodynamics in the Development of Antimicrobial Medicinal Products. Available online: https://www.ema.europa.eu/en/documents/scientific-guideline/guideline-usepharmacokinetics-pharmacodynamics-development-antimicrobial-medicinal-products_en.pdf (accessed on 19 February 2021).

43. User Guide-Simulx. Available online: http:/ / simulx.webpopix.org/userguide/ (accessed on 19 February 2021).

44. Bafadhel, M.; McKenna, S.; Terry, S.; Mistry, V.; Reid, C.; Haldar, P.; McCormick, M.; Haldar, K.; Kebadze, T.; Duvoix, A.; et al. Acute exacerbations of chronic obstructive pulmonary disease: Identification of biologic clusters and their biomarkers. Am. J. Respir. Crit. Care Med. 2011, 184, 662-671. [CrossRef]

45. Jacobs, D.M.; Pandit, U.; Sethi, S. Acute exacerbations in chronic obstructive pulmonary disease: Should we use antibiotics and if so, which ones? Curr. Opin. Infect. Dis. 2019, 32, 143-151. [CrossRef] [PubMed]

46. Bensman, T.J.; Wang, J.; Jayne, J.; Fukushima, L.; Rao, A.P.; D'Argenio, D.Z.; Beringer, P.M. Pharmacokinetic-pharmacodynamic target attainment analyses to determine optimal dosing of ceftazidime-avibactam for the treatment of acute pulmonary exacerbations in patients with cystic fibrosis. Antimicrob. Agents Chemother. 2017, 61, e00988-17. [CrossRef] [PubMed]

47. Li, S.; Xie, F. Population pharmacokinetics and simulations of imipenem in critically Ill patients undergoing continuous renal replacement therapy. Int. J. Antimicrob. Agents 2019, 53, 98-105. [CrossRef] [PubMed]

48. Muller, A.E.; Punt, N.; Mouton, J.W. Optimal exposures of ceftazidime predict the probability of microbiological and clinical outcome in the treatment of nosocomial pneumonia. J. Antimicrob. Chemother. 2013, 68, 900-906. [CrossRef]

49. Mouton, J.W.; Punt, N.; Vinks, A.A. A retrospective analysis using monte carlo simulation to evaluate recommended ceftazidime dosing regimens in healthy volunteers, patients with cystic fibrosis, and patients in the intensive care unit. Clin. Ther. 2005, 27, 762-772. [CrossRef]

50. MacVane, S.H.; Kuti, J.L.; Nicolau, D.P. Clinical pharmacodynamics of antipseudomonal cephalosporins in patients with ventilator-associated pneumonia. Antimicrob. Agents Chemother. 2014, 58, 1359-1364. [CrossRef]

51. Couffignal, C.; Pajot, O.; Laouénan, C.; Burdet, C.; Foucrier, A.; Wolff, M.; Armand-Lefevre, L.; Mentré, F.; Massias, L. Population pharmacokinetics of imipenem in critically Ill patients with suspected ventilator-associated pneumonia and evaluation of dosage regimens: Population pharmacokinetics of imipenem in ICU. Br. J. Clin. Pharmacol. 2014, 78, 1022-1034. [CrossRef]

52. Huang, Y.; Yang, J.; Xie, J.; Liu, L.; Liu, S.; Guo, F.; Qiu, H.; Yang, Y. Association between pathophysiology and volume of distribution among patients with sepsis or septic shock treated with imipenem: A prospective cohort study. J. Infect. Dis. 2020, 221, S272-S278. [CrossRef]

53. Baptista, J.P. Augmented renal clearance. In Antibiotic Pharmacokinetic/Pharmacodynamic Considerations in the Critically Ill; Springer: Berlin/Heidelberg, Germany, 2018; pp. 125-150.

54. Hobbs, A.L.V.; Shea, K.M.; Roberts, K.M.; Daley, M.J. Implications of augmented renal clearance on drug dosing in critically Ill patients: A focus on antibiotics. Pharmacotherapy 2015, 35, 1063-1075. [CrossRef]

55. O'Donnell, J.N.; Bidell, M.R.; Lodise, T.P. Approach to the treatment of patients with serious multidrug-resistant Pseudomonas aeruginosa infections. Pharmacotherapy 2020, phar.2449. [CrossRef]

56. Zasowski, E.J.; Rybak, J.M.; Rybak, M.J. The $\beta$-Lactams strike back: Ceftazidime-avibactam. Pharmacotherapy 2015, 35, 755-770. [CrossRef] [PubMed]

57. Prescott, W.A.; Gentile, A.E.; Nagel, J.L.; Pettit, R.S. Continuous-infusion antipseudomonal beta-lactam therapy in patients with cystic fibrosis. P T 2011, 36, 723-763. [PubMed]

58. Keel, R.A.; Sutherland, C.A.; Crandon, J.L.; Nicolau, D.P. Stability of doripenem, imipenem and meropenem at elevated room temperatures. Int. J. Antimicrob. Agents 2011, 37, 184-185. [CrossRef] [PubMed]

59. Tada, T.; Nhung, P.H.; Miyoshi-Akiyama, T.; Shimada, K.; Tsuchiya, M.; Phuong, D.M.; Anh, N.Q.; Ohmagari, N.; Kirikae, T. Multidrug-resistant sequence type 235 pseudomonas aeruginosa clinical isolates producing IMP-26 with increased carbapenemhydrolyzing activities in Vietnam. Antimicrob. Agents Chemother. 2016, 60, 6853-6858. [CrossRef] 
60. De Velde, F.; Mouton, J.W.; de Winter, B.C.M.; van Gelder, T.; Koch, B.C.P. Clinical applications of population pharmacokinetic models of antibiotics: Challenges and perspectives. Pharmacol. Res. 2018, 134, 280-288. [CrossRef] [PubMed]

61. Jonsson, E.N.; Wade, J.R.; Karlsson, M.O. Comparison of some practical sampling strategies for population pharmacokinetic studies. J Pharm. Biopharm. 1996, 24, 245-263. [CrossRef] [PubMed] 